\title{
PERUNAN MUKULAIN KUIVA-AINEPITOISUUDEN VAIHTELUISTA
}

\author{
Kaiho Laurila ja Simo Antila \\ Yliopiston kasvipatologian laitos, Viikin koetila, Malmi
}

Johdanto

Saapunut 9. 4. 1956 .

Perunan mukulan kuiva-ainepitoisuus on riippuvainen lajikeominaisuuksista ja kasvukauden aikana vallitsevista ulkoisista olosuhteista $(12,13)$. Pitkänä kasvukautena, sekä suotuisissa kosteus- ja lämpötilaolosuhteissa mukulain kuiva-ainepitoisuus muodostuu suhteellisen suureksi $(3,12,13)$. Täysin tuleentuneissa mukuloissa on korkeampi kuiva-ainepitoisuus kuin keskenkasvuisissa $(1,3,11,12)$. Perunan mukulasadon määrän ja laadun kehitykselle on optimaalinen maaperän lämpötila $13-26^{\circ} \mathrm{C}(5)$. Suomen olosuhteissa on varsinaisen kasvukauden (kesäelokuun) lämpötilan osuus ratkaiseva mukulain kuiva-ainepitoisuuden kehitykselle (12). Toisenlaisissa olosuhteissa saattavat puolestaan maaperän kosteussuhteet olla kuiva-ainepitoisuuden vaihteluiden suurimpana syynä (13). Eräiden tutkimusten mukaan $(3,9)$ jää mukulain kuiva-ainepitoisuus pienemmäksi erityisen kuivassa kuin kosteassa maassa, mutta päinvastaisiakin tuloksia on esitetty (11). Sitä paitsi on mukulain kuiva-ainepitoisuus yleensä suurempi kivennäis- kuin turvemaan perunaviljelmissä $(12,13)$. Suuria kuiva-ainepitoisuusèroja ilmenee kuitenkin myös tasalaatuisessa pellossa kasvaneiden perunayksilöiden ja edelleen kunkin perunayksilön eri mukulain välillä (8). Tämä vaihtelu on ainakin jossakin määrin riippuvainen mukulain koosta (8). Niin ikään kuiva-aineen jakautuminen perunan mukular eri osiin on jonkin verran epätasaista. Eroavaisuuksia on tässä suhteessa todettu edelleen mukulan kuori- ja sisäosien $(4,7)$, samoin kanta- ja silmupuoliskojen välillä (4).

Helsingin yliopiston kasvipatologian laitoksessa on vuodesta 1947 lähtien selvitelty perunan lajiristeytyskloonien kasvullista muuntelua, perunan suhtautumista päivänpituuteen sekä sen ruton- ja kylmänkestävyyttä. Näissä tutkimuksissa on ilmennyt suuria lajikkeen- ja klooninsisäisiä mukulain kuiva-ainepitoisuuden vaihteluita. Siten on osoittautunut tarpeelliseksi selvittää lähemmin näiden vaihte- 


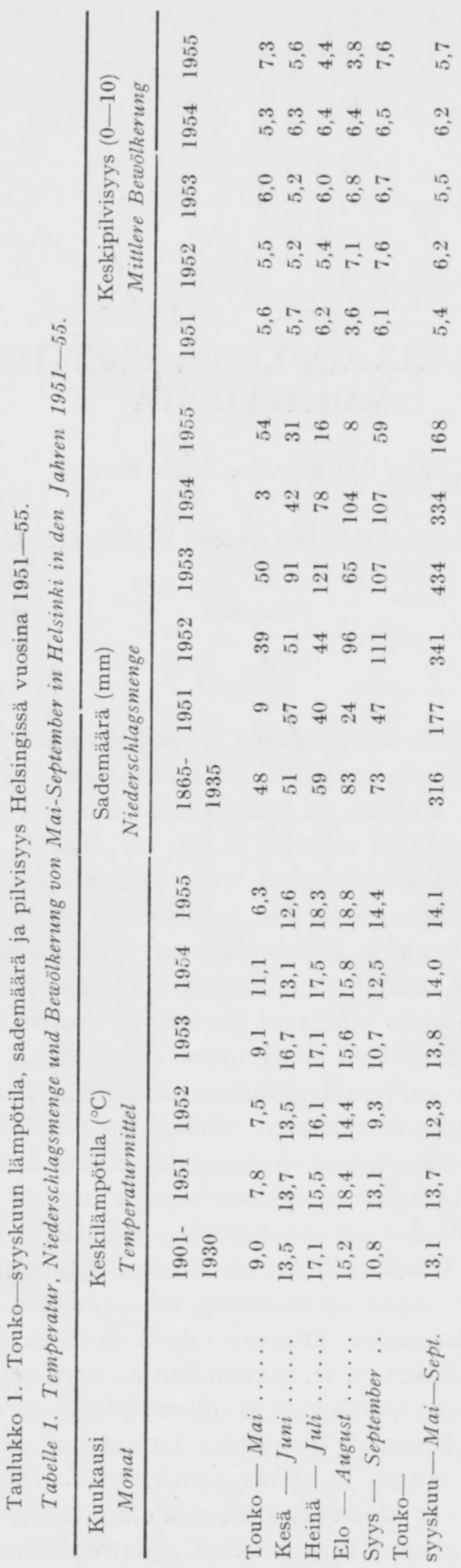




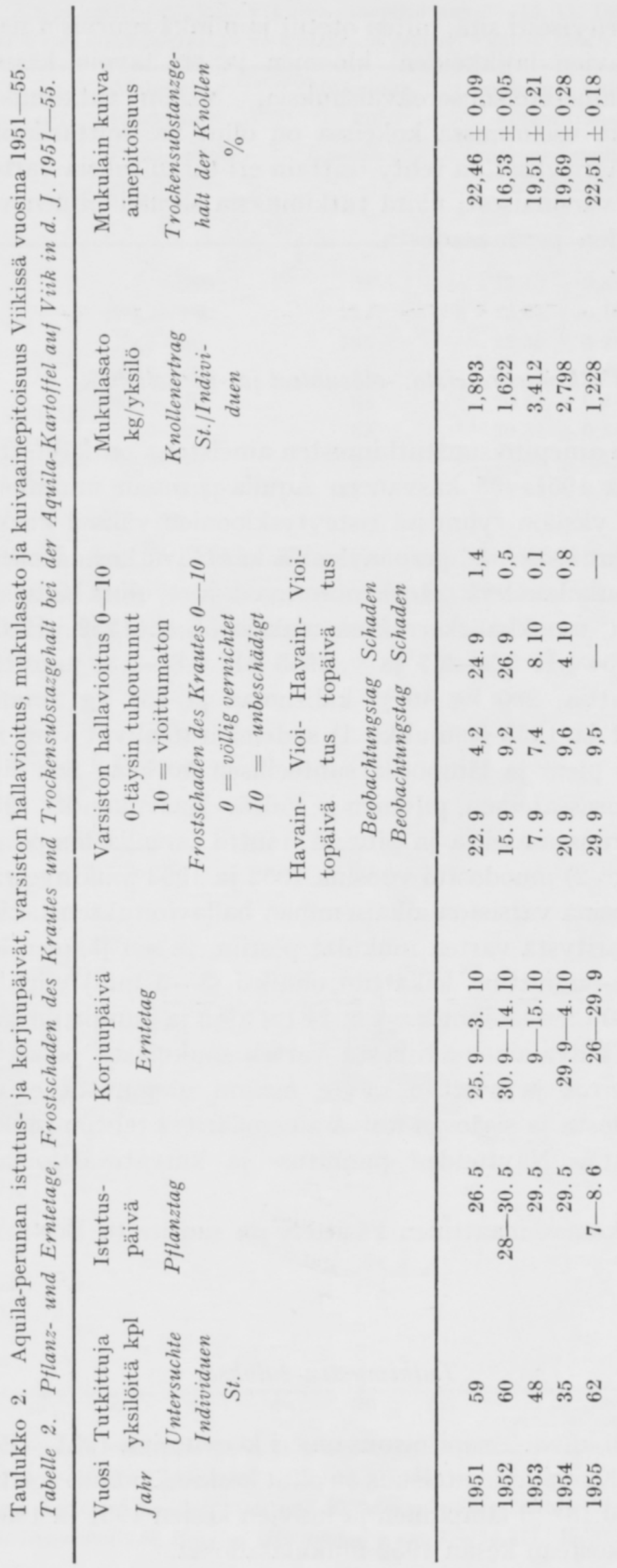


luiden luonnetta, erityisesti sitä, miten otetut ja minkä suuruiset näytteet parhaiten valaisevat tutkittavien lajikkeiden, kloonien ja eri tavoin käsiteltyjen perunaaineistojen kuiva-ainepitoisuuseroavaisuuksia. Näihin tutkimuksiin on valittu Aquila-peruna, joka useimmissa kokeissa on ollut ns. mittarilajikkeena. Kuivaainepitoisuuden määritykset on tehty osittain eri tarkoituksia varten järjestettyjen kokeiden, osittain varsinaisesti näitä tutkimuksia silmälläpitäen v. 1955 järjestettyjen kenttäkokeiden perunasadosta.

\section{Tutkimusaineisto, -olosuhteet ja-menetelmät}

Perunan kuiva-ainepitoisuustutkimusten aineistona on käytetty Viikin opetusja koetilalla kesinä 1951-55 kasvaneen Aquila-perunan mukuloita. Nämä ovat kasvaneet kolmen yksilön ryhmissä risteytyskloonien välissä koekentän eri osissa. Kesällä 1955 on ollut lisäksi 36 perunayksilöä käsittävä koe. Kokeissa on käytetty 120 sm:n rivi- ja mukulavälejä. Koekentän maalaji on ollut hietaista hietasavea hietaista liejusavea; muokkauskerroksen reaktio oli v. $1952 \mathrm{pH} 5.8$-6.9, v. 1953 pH 5.7-6.3, v. 1954 pH 5.3-5.7 ja v. 1955 pH 5.8-6.3, vuosittainen lannoitus $300 \mathrm{~kg}$ superfosfaattia, $200 \mathrm{~kg} 40 \%$ kalisuolaa ja $150 \mathrm{~kg}$ ammoniumsulfaattia. Kasvukausien 1951 ja 1955 (taulukko 1) sademäärät olivat vain noin puolet normaalista, pilvisyys pieni ja lämpötila suhteellisen korkea. Sen sijaan kasvukausi 1952 oli erittäin runsassateinen, pilvinen ja viileä. Kasvukaudet 1953 ja 1954 olivat myös suhteellisen runsassateisia ja pilvisiä, mutta samalla lämpimiä (6). Perunan kasvuaika (taulukko 2) muodostui vuosina 1952 ja 1953 jonkinverran lyhyemmäksi kuin muina koevuosina varsiston aikaisemman hallavioituksen takia.

Kuiva-ainemääritystä varten mukulat pestiin, ja sen jälkeen kun niiden pinta oli kuivahtanut ne punnittiin, leikattiin ohuiksi $(3-5 \mathrm{~mm})$ viipaleiksi, kuivattiin kuivauskaapissa 120 C:en lämpötilassa n. 24 t:n ajan ja punnittiin uudelleen. Mukulan ulkokerroksen kuiva-ainemääritystä varten mukulasta poistettiin n. 2 mmn vahvuinen kuorikerros ja otettiin näyte mallon ulommista osista; sen jälkeen poistettiin osa mallosta ja sisäosan kuiva-ainemääritys tehtiin mukulan ydinosasta otetusta kappaleesta. Näytteiden punnitus- ja kuivatusastioina olivat Petrinmaljain kannet.

Aineiston tilastomatemaattinen käsittely on suoritettu BonniERin ja TEDinin (2) mukaisesti.

\section{Tutkimusten tulokset}

Aquila-perunan kuiva-ainepitoisuus on eri koevuosina $1951-55$ vaihdellut suuresti (taulukko 2). Kuiva-ainepitoisuus on ollut keskimääräistä korkeampi (22.46 \pm $0.09 \%$ ja $22.51 \pm 0.18 \%$ ) lämpimien ja kuivien kesien 1951 ja 1955 , alin $(16.53 \pm$ $0.05 \%$ ) viileän ja kostean kesän 1952 mukulasadossa. 
Taulukko 3. Eri kokoisten mukulain kuiva-ainepitoisuus 7-15. 11. 1955.

Tabelle 3. Der Trockensubstanzgehalt verschiedenen grosser Knollen vom 7.-15. 11. 1955.

\begin{tabular}{ccc}
$\begin{array}{c}\text { Mukulain } \\
\text { tuorepaino } \\
\begin{array}{c}\text { Frischgewicht } \\
\text { der Knollen }\end{array}\end{array}$ & $\begin{array}{c}\text { Mukuloita } \\
\mathrm{kpl} \\
\text { Knollen St. }\end{array}$ & $\begin{array}{c}\text { Mukulain kuiva- } \\
\text { ainepitoisuus } \\
\text { Trockensubstanzgehalt } \\
\text { der Knollen } \\
\%\end{array}$ \\
\hline-200 & & \\
$199,9-100$ & 28 & $22,13 \pm 0,32$ \\
$99,9-50$ & 132 & $22,64 \pm 0,18$ \\
$49,9-40$ & 195 & $22,36 \pm 0,22$ \\
$39,9-30$ & 41 & $21,18 \pm 0,67$ \\
$29,9-20$ & 68 & $20,21 \pm 0,43$ \\
$19,9-10$ & 63 & $20,31 \pm 0,58$ \\
$9,9-0,1$ & 96 & $19,03 \pm 0,43$ \\
& 135 & $18,83 \pm 0,33$
\end{tabular}

Erikokoisten mukulain kuiva-ainepitoisuuseroja tutkittaessa (taulukko 3) on todettu, että pienimmissä ( $0.1 — 20 \mathrm{~g}$ :a painavissa) mukuloissa on ollut jonkinverran pienempi kuiva-ainepitoisuus kuin muissa.

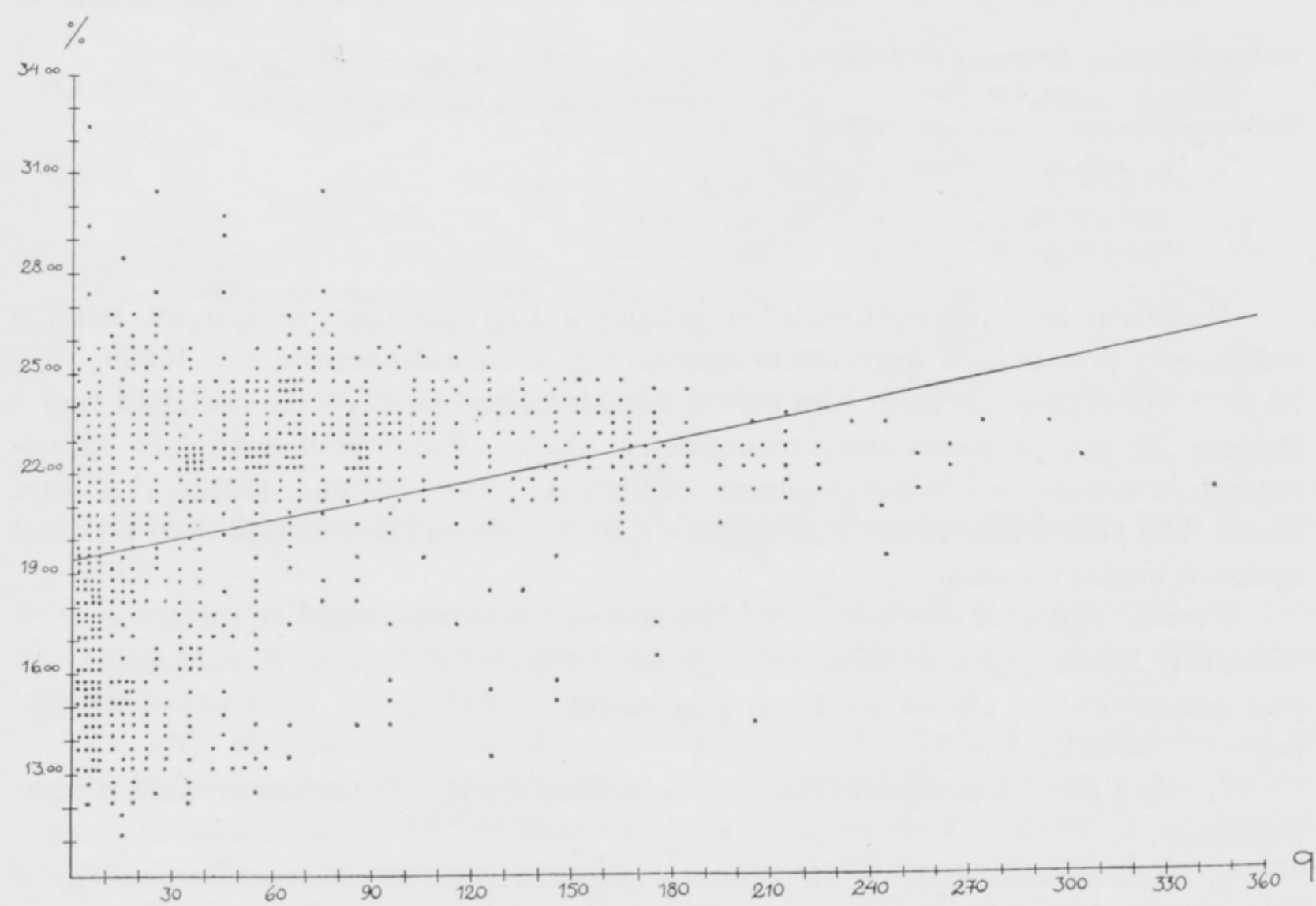

Piirros 1. Aquila-perunan mukulain koon ja kuiva-ainepitoisuuden vuorosuhde. Tutkittu 36 yksilöä, joissa yhteensä 758 mukulaa (määritys 7-15. 11. 1955).

Fig. 1. Korrelation zwischen Knollengrösse und Trockensubstanzgehalt der Aquila-Kartoffel. Untersucht 36 Individuen mit insgesamt 758 Knollen (Bestimmung am 7.-15. 11. 1955). 
Taulukko 4. Perunan mukulan eri osien kuiva-ainepitoisuus.

Tabelle 4. Der Trockensubstanzgehalt verschiedener Teile der Kartoffelknolle.

\begin{tabular}{|c|c|c|c|c|c|}
\hline $\begin{array}{c}\text { Mukulan osa } \\
\text { Knollenteil }\end{array}$ & $\begin{array}{l}\text { Vuosi } \\
\text { Jahr }\end{array}$ & $\begin{array}{l}\text { Yksilöitä } \\
\text { kpl } \\
\text { IndividuenSt. }\end{array}$ & $\begin{array}{l}\text { Mukuloita } \\
\text { kpl } \\
\text { Knollen St. }\end{array}$ & $\begin{array}{l}\text { Kuiva-aine- } \\
\text { pitoisuus } \\
\text { Trockensubstanz- } \\
\text { gehalt }\end{array}$ & $\begin{array}{c}\text { Erotus } \\
\text { Unterschied } \\
\%\end{array}$ \\
\hline Silmupuolisko - Kronenende & 1952 & 3 & 39 & 19,76 & \multirow[b]{2}{*}{$2,57 \pm 0,49$} \\
\hline Kantapuolisko - Nabelende & 1952 & 3 & 39 & 22,33 & \\
\hline Silmupuolisko-Kronenende & 1955 & 15 & 75 & 20,54 & \multirow{2}{*}{$1,79 \pm 0,67$} \\
\hline Kantapuolisko - Nabelende & 1955 & 15 & 75 & 22,33 & \\
\hline Yläpuolisko - Obeve Hälfte & 1952 & 4 & 20 & 16,48 & \multirow{2}{*}{$0,41 \pm 0,48$} \\
\hline Alapuolisko - Untere Hälfte & 1952 & 4 & 20 & 16,89 & \\
\hline Yläpuolisko - Obere Hälfte & 1955 & 15 & 75 & 21,34 & \multirow{2}{*}{$1,30 \pm 0,66$} \\
\hline Alapuolisko - Untere Hälfte & 1955 & 15 & 75 & 22,64 & \\
\hline Oikea puolisko — Rechte Hälfte & 1952 & 3 & 20 & 18,38 & \multirow{2}{*}{$0,03 \pm 0,43$} \\
\hline Vasen puolisko -- Linke Hälfte & 1952 & 3 & 20 & 18,41 & \\
\hline Mallon sisäosa - Innerer Teil & 1954 & 1 & 9 & 17,88 & \multirow[b]{2}{*}{$5,07 \pm 1,14$} \\
\hline $\begin{array}{r}\text { des Fleisches } \\
\text { Mallon ulkokerros - Aussen- } \\
\text { sicht des Fleisches }\end{array}$ & 1954 & 1 & 9 & 22,95 & \\
\hline
\end{tabular}

Mukulain kuiva-ainepitoisuuden ja niiden tuorepainojen kesken on todettu vallitsevan positiivinen korrelaatio (piirros 1), korrelaatiokerroin $\mathrm{r}=0.299, \mathrm{v}^{2}=$ $73.96 * * *$ ja regressiokerroin $\mathrm{b}=0.201$. Luokkavälinä on käytetty mukulan tuoresadossa 30 g:a ja kuiva-ainepitoisuudessa $3 \%$ :a. Pienimpien mukulain kuivaainepitoisuudessa on ilmennyt suuria vaihteluja, jotka osaltaan saattavat johtua kesän 1955 poikkeuksellisista sääsuhteista, jolloin ankara kuivuus keskeytti pitkäksi ajaksi mukulain kasvun.

Saman mukulan eri osien välisten kuiva-ainepitoisuuserojen selvittämiseksi tutkittiin Aquila-perunan mukuloita, joiden tutkittavat osat merkittiin jo kasvupaikalla, mukulain ollessa vielä varsissa kiinni. Tutkimusten tulokset olivat seuraavat (taulukko 4).

1. Mukulain kantapuoliskon kuiva-ainepitoisuus oli suurempi kuin silmupuoliskon.

2. Kun mukulat halkaistiin pituussuunnassa kahtia, oli maanpinnan puoleisten (ylä-)puoliskojen kuiva-ainepitoisuus pienempi kuin mukulan alapuoliskojen.

3. Kun mukulat halkaistiin pituussuunnassa kahtia, ei kiinnityskohdasta katsoen oikean ja vasemman puoliskon kuiva-ainepitoisuuksien välillä ollut havaittavaa eroa. 


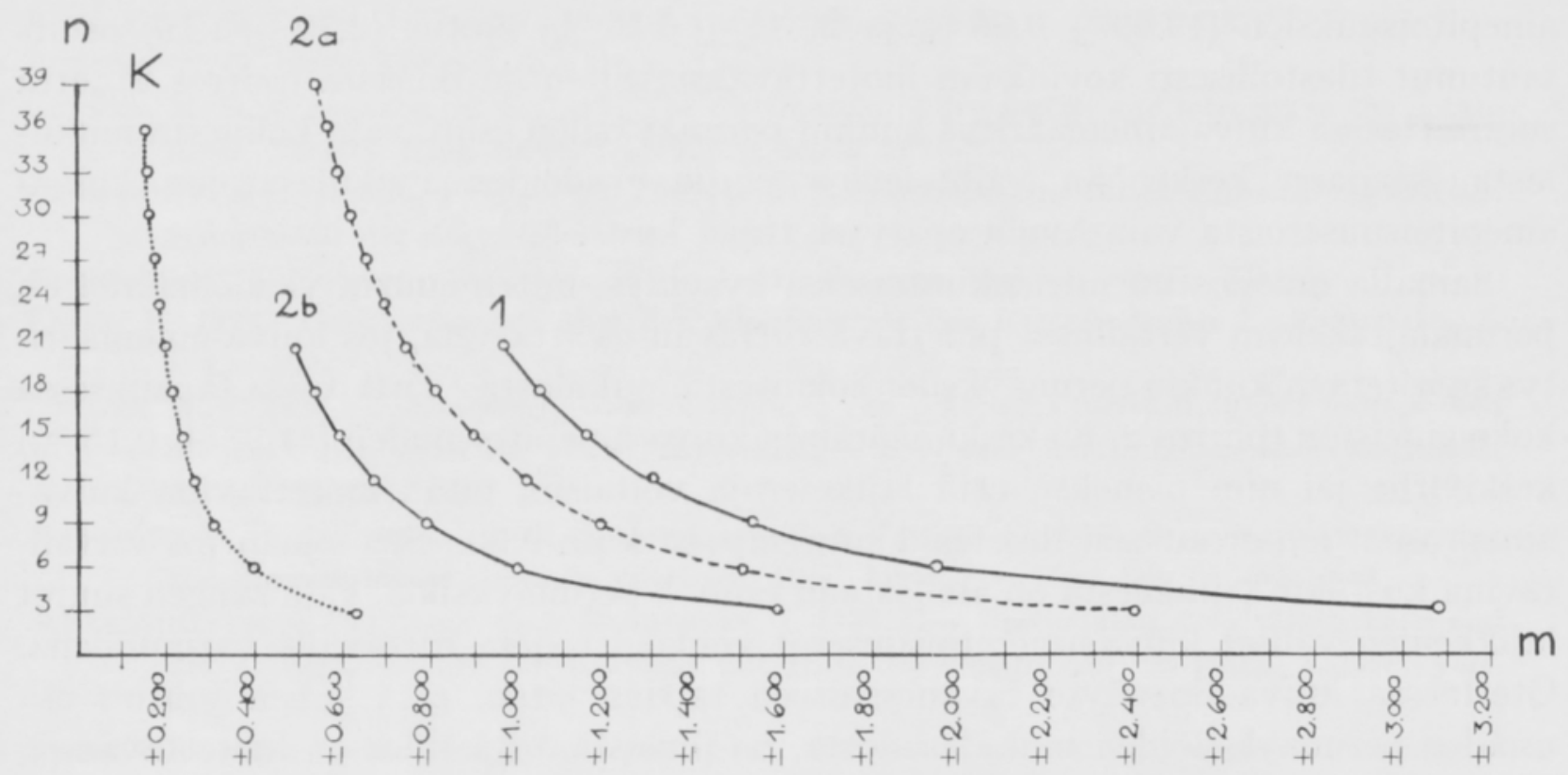

Piirros 2. Mukulain lukumäärän (n; käyrät 1, 2a, 2b) ja yksilöiden lukumäärän (n; käyrä K) vaikutus kuiva-ainepitoisuusarvojen keskiarvon keskivirheen $(\mathrm{m})$ suuruuteen.

Fig. 2. Einfluss von Knollenzahl (n; Kurven 1, 2a, 2b) und Individuenzahl (n; Kurve K) auf die Grösse des mittleven Fehlers $(m)$ im Mittelwert der Trockensubstanzgehaltwerte.

Mukulaluvun mukaan lasketut käyrät:

Nach der Knollenzahl berechnete Kurven:

yksilö 1, 21 mukulaa - Ind. 1. 21 Knollen

\#... " $2 \mathrm{a}, 39$ " 39 " $2 a, 39$ "

" $2 \mathrm{~b}, 21 \quad$ " " $2 b, 21$ "

Yksilöluvun mukaan laskettu käyrä:

Nach der Knollenzahl berechnete Kurven:

............. K, yksilöt $1-36,21.1$ mukulaa/yksilö

K, Individuen 1-36, 21.1 Knollen/Ind.
Mukulain kuiva-ainepit.

Trockensubsz. d. Knoll.

$\%$

$19.69 \pm 0.98$

$20.72 \pm 0.55$

$22.41 \pm 0.50$

4. Mukulan mallon ulkokerroksen kuiva-ainepitoisuus oli suurempi kuin mallon sisäosan.

Mukulan eri osien väliset kuiva-ainepitoisuuserot ovat olleet suhteellisen pienet, mukulan mallon ulkokerroksen ja sisäosan välistä kuiva-ainepitoisuuseroa lukuunottamatta.

V. 1955 suoritetussa erikoiskokeessa, jossa perunayksilöitä (Aquila) oli 36 ja niissä muodostuneiden mukulain luku 758, tutkittiin jokaisen mukulan kuivaainepitoisuus erikseen. Niiden kuiva-ainepitoisuus osoittautui hyvin vaihtelevaksi (piirros 1). Vastaava vaihtelu myös kunkin perunayksilön puitteissa oli varsir tuntuva; tätä kuvaavat mm. kahden mielivaltaisesti valitun perunayksilön mukulain kuiva-ainepitoisuuksien keskiarvon keskivirheet (piirros 2, yksilöt 1 ja 2). Siinäkin tapauksessa, että pienimmät (alle $10 \mathrm{~g}$ ) mukulat jätettiin tutkimuksen ulkopuolelle ja kummastakin perunayksilöstä määritettiin 21 mukulan kuiva-ainepitoisuus, ei näiden yksilöiden varsin tuntuvalta näyttänyt mukulain keskimääräisten kuiva- 
ainepitoisuuksien $(19.69 \pm 0.98 \%$ ja $22.41 \pm 0.50 \%)$ erotus $(2.72 \pm 1.10)$ osoittautunut tilastollisesti kovinkaan luotettavaksi. Siten on ilmeistä (piirros 2), että suoritettaessa kuiva-ainemääritys kunkin perunayksilön esim. vain kolmesta mukulasta, saadaan keskenään vaihtelevien perunayksilöiden mukulasatojen kuivaainepitoisuuseroista vain hyvin epätyydyttävä kuva.

Samalla muodostuu mielenkiintoiseksi kysymys, miten suurta yksilömäärää on perunalajikkeiden vertailussa pidettävä riittävän osoittavana, jos kuiva-ainemääritys suoritetaan kunkin perunayksilön jokaisesta mukulasta. Tutkitussa tapauksessa koko aineiston (piirros 2, K) keskimääräisen kuiva-ainepitoisuuden $(21.98 \pm 0.15 \%$ ) keskivirhe jäi niin pieneksi, että lajike-eroja voitaisiin pitää luotettavina kuivaaineprosenttien erotuksen ilmetessä suurempana kuin 0.50. Sen sijaan jos vertailtavina kustakin lajikkeesta on ainoastaan esim. 3 perunayksilöä, vain sangen suuret lajikkeiden väliset kuiva-ainepitoisuuserot voidaan todeta riittävällä varmuudella. Otettaessa kuiva-ainenäyte tavanomaiseen tapaan siten, että siihen joutuu osa useiden perunayksilöiden mukulasadosta, on ilmeistä, että tulos on luotettavampi, jos tutkittavaan näytteeseen ei oteta kaikkein pienimpiä mukuloita (piirros 2, yksilö 2 b) kuin jos mukulan kokoon ei kiinnitetä mitään huomiota (piirros 2, yksilö 2 a). Todennäköisesti (piirros 1) keskikokoiset mukulat soveltuvat kuiva-ainemääritykseen kaikkein parhaiten.

\section{Yhteenveto}

Edellä selostettujen tutkimusten perusteella voidaan tehdä seuraavat päätelmät.

1. Mukulain kuiva-ainepitoisuus on ollut suurempi normaalia lämpimämpien, aurinkoisempien ja vähäsateisempien kuin keskimääräistä runsassateisempien, viileämpien ja pilvisempien kesien perunasadossa.

2. Tietyn perunalajikkeen eri mukulain väliset kuiva-ainepitoisuuserot ovat olleet huomattavia. Mukulain tuorepainon ja kuiva-ainepitoisuuden kesken on todettu vallitsevan positiivinen korrelaatio.

3. Mukulain kantapuoliskon kuiva-ainepitoisuus on ollut suurempi kuin silmupuoliskon. Samoin on mukulan alapuoliskon kuiva-ainepitoisuus ollut suurempi kuin yläpuoliskon. Niinikään on mukulan mallon ulkokerroksen kuiva-ainepitoisuus ollut suurempi kuin mallon sisäosan. Kuitenkin mukulan eri osien välillä esiintyneet kuiva-ainepitoisuuserot ovat olleet pienempiä kuin eri mukulain väliset.

4. Lisäksi on selvitetty perunayksilöiden mukulain ja perunayksilöiden koko mukulasatojen kuiva-ainepitoisuuden vaihtelun suuruutta ja kuvattu mukula- ja yksilöluvun vaikutusta kuiva-ainepitoisuuden keskiarvon keskivirheen suuruuteen tietyn peruna-aineiston puitteissa.

\section{KIRJALLISUUTTA}

1) Appleman, C. O.\& Miller, E. V. 1926. A chemical and physiological study of maturity in potatoes J. Agric. Res. 33: $569-577$. 
2) Bonnier, G. \& Tedin, O. 1940. Biologisk variationsanalys. 325 s. Stockholm.

3) Burton, W. G. 1948. The potato. 319 s. London.

4) Glynne, M. D. \& Jackson, V. G. 1919. The distribution of dry matter and nitrogen in the potato tuber, variety King Edward. J. Agric. Sci. 9: 237-258.

5) Gäumann, E. \& HÄFliger, E. 1950. Die Einfluss der Bodentemperatur auf die Entwicklung und den Schorfbefall der Kartoffelknollen. Phytopath. Z. 16: 85-105.

6) Kuukausikatsaus Suomen sääoloihin. 1951-1955. Ilmatiet. keskusl. vuosik. 44-48.

7) Lepik, E. 1929. Untersuchungen über den Biokemismus der Kartoffelfäulen I. Phytopath. Z. 1: $49-109$.

8) Lunden, A. P. 1938. Undersøkelser over variasjonen i en potetsorts tørrstoffinnhold bestemt ved hjelp av den specifice vekt. Årsmelding om Norges landbr.høisk. åkervekstforsøk. 47: $62-79$.

9) Mentzger, C. H. \& Tobiska, J. W. \& Douglass, E. \& Vail, C. E. 1937. Some factors influencing the composition of Colorado potatoes. Proc. Amer. Soc. Hort. Sci. 35: 635-643.

10) Scheele, C. von \& Svensson, G. \& Rasmusson, J. 1936. Die Bestimmung des Stärkegehalts und der Trockensubstanz der Kartoffel mit Hilfe des spezifischen Gewichts. Landw. Vers. Stat. 127: $67-96$.

11) Smith, O. \& Nash, L. B. 1941. Potato quality III. Relation of soil reaction, irrigation and mineral nutrition to cooking quality. Proc. Amer. Soc. Hort. Sci. 38: 507-512.

12) Tuorila, P. 1929. Untersuchungen über die chemische Zusammensetzung der Kartoffeln in Finnland. S. Suovilj. yhd. tiet. julk. 11: 1-73.

13) Wager, A. G. 1946. Quality of potatoes in relation to soil and season I. The content of dry matter. J. Agric. Sci. 36: 207-213.

\title{
REFERAT:
}

\section{ÜBER SCHWANKUNGEN IM TROCKENSUBSTANZGEHALT DER KARTOFFELKNOLLEN}

\author{
Kaiho Laurila und Simo Antila \\ Pflanzenpathologisches Institut der Universität Helsinki
}

Bei den Untersuchungen sind in den Jahren 1951-55 auf dem Lehr- und Versuchsgut Viik gewachsene Knollen der Kartoffel Aquila benutzt worden. Man hat die Unterschiede im Trockensubstanzgehalt, die zwischen den verschieden grossen Knollen und zwischen verschiedenen Teilen einer und derselben Knolle bestehen, ermittelt. Ausserdem ist die Grösse der Schwankung im Trockensubstanzgehalt der Knollen eines Kartoffelindividuums und der gesamten Knollenerträge der Kartoffelindividuen untersucht (Fig. 1) und die Wirkung der Knollen- und der Individuenzahl auf die Grösse des mittleren Fehlers im Mittelwert des Trockensubstanzgehaltes (Fig. $\boldsymbol{z}$ ) im Rahmen eines bestimmten Kartoffelmaterials abgebildet worden. Die Untersuchungsergebnisse erweisen (Tab. 2), dass der Trockensubstanzgehalt der Knolle in mehr als normal warmen, sonnigen und wolkenarmen Sommern grösser als im Kartoffelertrag überdurchschnittlich warmer, sonniger und wolkenarmer Sommer gewesen ist. Die Unterschiede im Trockengehalt der verschiedenen Knollen sind beträchtlich gewesen (Tab. 3). Zwischen Frischgewicht- und Trockensubstanzgehalt der Knollen ist eine positive Korrelation festgestellt worden (Fig. 1). Der Trockenstoffgehalt des Nabelende der Knolle ist grösser als der des Kronenende gewesen. Ebenso ist der Trockenstoffgehalt in der Aussenschicht des Fleisches der Knolle grösser als im inneren Teil des Fleisches ausgefallen (Tabelle 4). Die Unterschiede im Trockensubstanzgehalt der verschiedenen Teile der Knolle sind geringer als zwischen den verschiedenen Teilen der Knolle gewesen. 